\title{
Prelicensure Nursing Students Developing Clinical Judgment Through Emotional Intelligence: A Qualitative Interpretive Descriptive Study
}

\author{
Michelle Bussard \\ School of Nursing, Bowling Green State University, Bowling Green, Ohio, USA
}

\section{Email address:}

bussarm@bgsu.edu

\section{To cite this article:}

Michelle Bussard. Prelicensure Nursing Students Developing Clinical Judgment Through Emotional Intelligence: A Qualitative Interpretive Descriptive Study. American Journal of Nursing Science. Vol. 9, No. 6, 2020, pp. 411-416. doi: 10.11648/j.ajns.20200906.14

Received: October 29, 2020; Accepted: November 11 DD, 2020; Published: November 19, 2020

\begin{abstract}
Clinical judgment is an essential skill required for nurses to provide safe, quality patient care. Nurse educators must develop effective teaching strategies to assist prelicensure nursing students in developing clinical judgment skills. The objective of this study was to determine if a teaching strategy focused on the affective domain of learning and emotional intelligence could be an effective strategy to promote the development of clinical judgment. A guest speaker was invited to the classroom and provided her "lived experience" with multiple sclerosis, which provided a storytelling method of learning. An interpretive descriptive qualitative study was conducted with twenty-one prelicensure diploma registered nursing students enrolled in a medical-surgical nursing course (in the United States of America). Tanner's Clinical Judgment Model (noticing, interpreting, responding, and reflecting) was used as the theoretical framework to guide data analysis. Four themes emerged from the data: 1) attentive listening (noticing), 2) understanding the patient's experience (interpreting), 3) compassionate and empathetic care (responding), and 4) treat the patient as a person, not as a disease (reflecting). Results indicated that storytelling via "lived experiences" is an effective teaching strategy which promotes learning through the affective domain and emotional intelligence while also assisting students in developing clinical judgment. Clinical judgment skills are essential for the graduate nurse transitioning to practice.
\end{abstract}

Keywords: Emotional Intelligence, Lived Experience, Affective Learning Domain, Storytelling, Clinical Judgment

\section{Introduction}

Prelicensure registered nursing students are required to learn a tremendous amount of information prior to graduation. Therefore, nurse educators are tasked with providing effective teaching strategies to ensure that students graduate with necessary clinical judgment skills to provide safe, quality patient care. Traditionally, nurse educators have focused teaching strategies on cognitive and psychomotor learning domains. Providing lectures with PowerPoint slides and case studies is a common teaching strategy of the cognitive learning domain [1]. However, because students have limited to no experience with healthcare, they may find it difficult to relate to the topic or fully grasp the reality of the disease being taught, thus preventing the development of clinical judgment. Another traditional teaching strategy is the use of the skills laboratory for students to practice hands-on skills such as insertion of indwelling catheters, nasogastric tubes, or dressing changes using the psychomotor learning domain [2].

In addition to the cognitive and psychomotor domains of learning, the third learning domain is the affective learning domain and is a complex and underutilized educational strategy that has the potential to assist nursing students in developing effective clinical judgment skills. The affective domain is more difficult to teach compared to the cognitive and psychomotor because it focuses on the individual's personal attributes, values, self-reflection, and ability to be respectful and sensitive to the needs of others [3].

Emotional intelligence is one method of engaging and teaching to the affective domain of learning. Using emotional intelligence may help students visualize and understand a disease process through their emotions. Once an emotion is 
attached to something, one can relive that emotion in future patient encounters thus impacting how one cares for that patient [4-6]. A balance between the three learning domains is necessary for students to develop clinical judgment in prelicensure nursing programs $[6,7]$.

\section{Background}

\subsection{Bloom's Educational Learning Taxonomy}

Bloom's taxonomy for educational objectives began in 1949 when a group of educators convened with the goal of improving testing of students through the creation of test banks. These test banks were universal because they would measure the same educational outcome. This original taxonomy served as a method of providing consistent communication amongst educators, educational goals, assessments, and activities [8]. After many years of collecting and analyzing data, Bloom's original cognitive taxonomy was published [9]. The taxonomy was then revised in 2001 [1]. Educational learning taxonomy contains three domains of learning; cognitive [9], psychomotor [2], and affective [10]. Each domain has a hierarchical approach to learning with the assumption that each level must be achieved prior to advancing to the next level of learning.

The first educational domain is the cognitive learning domain. This domain reflects the theoretical knowledge obtained by a student. There are six categories within the revised cognitive learning domain and include: remembering (lowest level), understanding, applying, analyzing, evaluating, and creating (highest level) [1]. Teaching strategies to enhance the cognitive learning domain include lecture, PowerPoint, case studies, group discussions, gaming, and online learning modules.

The second educational domain is the psychomotor learning domain. This domain specifically focuses on the skills that require hands-on learning such as performing vital signs, physical assessment, dressing changes, manipulating equipment, and administering injections. The hierarchical categories for the psychomotor learning domain include imitation, manipulation, precision, articulation, and naturalization [2]. Skill acquisition through hands on experience in a skills laboratory or simulation laboratory is essential for students prior to going to the clinical setting and caring for patients.

The third educational domain is the affective learning domain, which focuses on the attitudes, values, and beliefs of the student. The hierarchical categories for the affective learning domain include receiving, responding, valuing, organization, and characterization by a value set [10]. Emotional intelligence is one teaching strategy for the affective learning domain.

\subsection{Storytelling}

Storytelling as a teaching strategy has been in the literature since the 1930's [11]. Storytelling is defined as; retelling of an event, situation, or patient experience, which stimulates ones imaginative thinking, invokes an emotional connection, a sense of personal beliefs, values, and attitudes, and formulates rapport with patients [11-18]. Storytelling is a powerful teaching strategy which has been discussed in length within nursing literature over the last 20 years and has a positive impact on the affective learning domain.

Storytelling has been used in nursing education as a teaching strategy with undergraduate students [16, 18]. Students were asked guided reflection questions after listening to a story to assist in developing clinical judgment. In this study, the author presented the patient story rather than an actual patient discussing their "lived experience" with an illness. Additionally, a study [3] discussed the affective learning domain to teach pharmacy students about various psychiatric disorders. The results of the study indicated that teaching strategies which challenged students' viewpoints and values promoted empathy, self-awareness, and compassion towards psychiatric patients while also developing critical thinking.

\section{Theoretical Models}

\subsection{Emotional Intelligence}

Emotional intelligence has been in the literature in a robust manner since its proposal in 1990. There have been varying degrees of understanding and measurement of emotional intelligence since its inception. The concept was originally based in the discipline of psychology and then was studied in business and management practices. Early studies of the concept led to misunderstanding of the authors original intent as well as conflict in measurement methods, characteristic traits, and definitions [19, 20].

Emotional intelligence is defined as "the ability to engage in sophisticated information processing about one's own and others' emotions and the ability to use this information as a guide to thinking and behavior" [20, p. 503]. Emotional intelligence has been noted to assist with a persons' problem-solving abilities [20]. A four-branch theoretical model for emotional intelligence includes; the ability to "(a) perceive emotions in oneself and others accurately, (b) use emotions to facilitate thinking, (c) understand emotions, emotional language, and the signals conveyed by emotions, and (d) manage emotions so as to attain specific goals" [20, p. 506]. Storytelling fits well into the second branch of the theoretical model; using "emotions to facilitate thinking" [20, p. 506].

The concept of emotional intelligence has moved to bedside nursing as researchers try to identify the effect that emotional intelligence has not only on emotions, compassion, leadership effectiveness, communication, and teamwork, but also upon cognitive factors such as clinical judgment, critical thinking, and conceptualization of data. Emotional intelligence can improve patient safety, patient outcomes, effective teamwork, and clinical skills of nurses [21]. Clinical decision making is improved when staff nurses are trained in emotional intelligence, thus suggesting that emotions should be actively 
engaged when students are taught cognitive material [22]. Additionally, [23] identified that engaging emotional intelligence was an indicator for academic success in first year accelerated nursing students. Whereas, [5] identified that emotional intelligence is an indicator of successful clinical performance with undergraduate nursing students.

\subsection{Clinical Judgment Model}

The Clinical Judgment Model was developed to depict, describe, and express how a nurse or student nurse develops clinical judgment [24]. Clinical judgment is defined as the ability to notice patient information, interpret the meaning of that data, formulate a response that is appropriate and individualized to the patient, and then reflect upon the experience. The four phases of clinical judgment are noticing, interpreting, responding, and reflecting. A nurse will progress through all four phases of the model as they develop and progress clinical judgment skills. First, the nurse notices information - this comes from hand-off report, reviewing the medical record, or communicating with the patient. Second, the nurse interprets the information that was gained in the noticing phase. Third, the nurse will respond through nursing interventions in an individualized and prioritized manner based on the data that was noticed and interpreted. Finally, the nurse will reflect upon the experience and determine what they did well and what areas need improvement in future patient situations. Reflection has been noted to be the key to developing and progressing clinical judgment [24].

\section{Purpose}

The purpose of this study was to determine if a teaching strategy (story telling through "lived experience") focused on the affective domain of learning and emotional intelligence could be an effective strategy to promote the development of clinical judgment in prelicensure registered nursing students enrolled in a medical-surgical nursing course.

\subsection{Methodology}

An interpretive descriptive qualitative study was conducted using a sample of 21 prelicensure registered nursing diploma students (predominately Caucasian females between 20-30 years of age) enrolled in a medical-surgical nursing course at one school of nursing in the United States of America. The nursing program is a three-year program; the first year consists of prerequisite, pre-nursing courses while years two and three are nursing core courses. The medical-surgical course is the second core nursing course located in the second year of the curriculum. An interpretive descriptive qualitative approach is a type of nursing research that allows a theoretical lens to assist in the development of themes generated from the qualitative data [25]. The theoretical lens used for the design of this study was Tanner's Clinical Judgment Model.

IRB approval was sought, and the study was deemed exempt by the Vice President of Quality and Patient Safety because it was a convenience sample, evaluation of a teaching method, retrospective review of data, and no potential for harm to students or their progression in the nursing program. The response to the qualitative question was voluntary and students were given the option to not respond. Informed consent was obtained when the student responded to the question (via email). Inclusion criteria; student was 18 years of age or older, the student attended class on the day of the guest speaker, and they emailed a response to the reflection question to the primary investigator. Exclusion criteria; student less than 18 years of age and the student did not attend class on the day of the guest speaker.

\subsection{Design}

The primary investigator for this study provided theoretical content for multiple sclerosis in a classroom setting. A lecture and PowerPoint presentation was provided along with group discussion. The next day, a guest speaker who has multiple sclerosis came to provide a "lived experience" through storytelling to the students. The speaker spoke about her symptoms prior to diagnosis, length of time it took for a diagnosis, treatment she has undergone, complications and side effects she has endured, number of hospitalizations she has had, her disability from work, level of fatigue, inability to have children, feelings of being judged by others, reliance on a mobility aide, and fears for her future. Students asked her questions throughout the presentation to gain a better understanding of her illness. At the completion of the presentation, the primary investigator sent an email to all students asking the following reflection questions: 1) what is one or two things you took away from the guest speakers presentation and 2) how do you foresee this impacting you as a nurse? Student response was voluntary and did not impact their grade or progression in the nursing program. Return of the email was considered informed consent. Data analysis did not occur until course completion to ensure a retrospective review and no impact on student progression.

\section{Results}

Data was analyzed by reading the student reflective responses thoroughly three times prior to formulating themes. Using interpretive description methodology [25], the theoretical lens of clinical judgment guided the thematic formation. The data was coded and categorized based on similar results and then compared to Tanner's clinical judgment model. Themes that were generated from the data include: attentive listening (noticing), understanding the patient's experience (interpreting), compassionate and empathetic care (responding), and treat the patient as a person, not as a disease (reflecting). See Table 1 for student comments related to each theme. 
Table 1. Qualitative Comments per Theme.

\begin{tabular}{|c|c|c|c|}
\hline $\begin{array}{l}\text { ve Listening } \\
\text { g) }\end{array}$ & $\begin{array}{l}\text { nderstanding the Patient's } \\
\text { xperience (Interpreting) }\end{array}$ & $\begin{array}{l}\text { Compassionate and Empathetic Care } \\
\text { (Responding) }\end{array}$ & $\begin{array}{l}\text { Treat the Patient as a Person, not as } \\
\text { a Disease (Reflecting) }\end{array}$ \\
\hline $\begin{array}{l}\text { "I think her story will help } \\
\text { me to always listen, } \\
\text { investigate, and advocate so } \\
\text { that my patients are heard." } \\
\text { "I learned to slow my role } \\
\text { as a nurse by taking the } \\
\text { extra five minutes to sit } \\
\text { down and listen to what a } \\
\text { patient has to say." } \\
\text { "Keeping in mind that } \\
\text { everyone's illness is } \\
\text { different, it would be better } \\
\text { to listen to what they have } \\
\text { to say and use what they } \\
\text { say to take better care of } \\
\text { them." } \\
\text { "The main thing I took } \\
\text { away from her story was to } \\
\text { listen to the patient." }\end{array}$ & $\begin{array}{l}\text { "I understand how multiple sclerosis } \\
\text { affects each person differently." } \\
\text { "Hearing her story put the disease in } \\
\text { perspective for me. Instead of } \\
\text { reading and memorizing the clinical } \\
\text { manifestations written out on a } \\
\text { PowerPoint, I was able to see how it } \\
\text { dramatically influences her } \\
\text { everyday life." } \\
\text { "After hearing her story, I feel like I } \\
\text { have a better understanding of what } \\
\text { is all involved with the illness." } \\
\text { "Nurses experience the illness for a } \\
\text { day, the patient lives with it." } \\
\text { "Hearing her speak about the } \\
\text { difficulties she faces and decisions } \\
\text { she has to make, reminds me that } \\
\text { everyone has been through things } \\
\text { that no one else knows anything } \\
\text { about." }\end{array}$ & $\begin{array}{l}\text { "Her story hit home and definitely opened } \\
\text { my eyes to just be a better person in general } \\
\text { and treat others with respect." } \\
\text { "To have compassion for each individual, } \\
\text { they are sick and want to get better." "I will } \\
\text { always remember to be compassionate to } \\
\text { my patients. I will also take time to attend } \\
\text { to their mental and emotional health." } \\
\text { "We need to be compassionate and let the } \\
\text { patients know that we are there to help them } \\
\text { get through their hospitalization period." } \\
\text { "I hope to always make my patients feel } \\
\text { dignified in their moments of } \\
\text { embarrassment." } \\
\text { "I wish to be respectful and sensitive to the } \\
\text { needs of the patients that I will be caring for } \\
\text { in the future." } \\
\text { "People are in the hospital for a reason and } \\
\text { they deserve to be cared for with } \\
\text { compassion." } \\
\text { "Making the patient feel comfortable and } \\
\text { relaxed during their time of need is my } \\
\text { drive for nursing." }\end{array}$ & $\begin{array}{l}\text { "As nurses, we need to remember that } \\
\text { we are not only treating the disease, } \\
\text { but we are also dealing with a human } \\
\text { being who has feelings." } \\
\text { "The guest speaker has made me have } \\
\text { a different approach to taking care of } \\
\text { patients. By really trying to get the full } \\
\text { story of the patient's problems with } \\
\text { living with the disease and not just } \\
\text { treating the disease." } \\
\text { "I think a lot of times it is easy to walk in } \\
\text { a room and focus on everything } \\
\text { medically you need to do for the patient } \\
\text { and forget that the person sitting there is } \\
\text { going through something." } \\
\text { "Underneath the disease is a person } \\
\text { with a heart and feelings." } \\
\text { "It is not always about getting assigned } \\
\text { tasks done. It's about providing the } \\
\text { absolute, quality care to your patient } \\
\text { and that includes treating them like a } \\
\text { human being instead of a task." }\end{array}$ \\
\hline
\end{tabular}

\section{Discussion}

The results of this study indicate that using storytelling is an effective teaching strategy for providing prelicensure nursing students with emotional intelligence through the affective domain of learning. Storytelling through "lived experiences" promotes the formation of emotions, thus assisting in developing clinical judgment skills. The themes indicate that students were able to connect emotions to a patient situation. Thus, they were able to notice, interpret, respond, and reflect in a manner to develop clinical judgment. Trustworthiness of data analysis followed Lincoln and Guba's evaluation criteria. Techniques for establishing credibility was established through prolonged engagement and persistent observation with the guest speaker and students and peer debriefing with another educator who is an expert in clinical judgment. Thick description in which the phenomenon can be translated to another patient situation was used to establish transferability. An inquiry audit was followed to establish dependability through an outside expert review of the data. Confirmability was established through an audit trail of raw data and data reduction [26].

One student comment indicated that this type of teaching strategy can be transferred to other patient encounters. The student is also an orderly (nurse's aide) in an acute care setting and stated: "I actually was able to put the things I learned from the guest speaker to the test. She taught me that patience is key. Even though these people are going through the toughest time of their life, they are still people. Today, I had the pleasure of taking care of an elderly man who was suffering from cancer and the treatment made him completely confused, so they made him a 1:1. The other orderlies were warning me about him before I went in, saying 'good luck and he was a tough one;' I approached the room differently. I went in and introduced myself and told him what I would be doing today. I managed to stay focused and tried to meet his needs, like calling his wife and getting him something to drink when his doctors changed his NPO status. I bathed him and combed his hair so he could look good for his wife. I took pride in my work today. I made him comfortable and happy. I made him feel like a person, which is exactly what our guest speaker taught us to do."

\section{Recommendations}

This study contributes to the nursing body of knowledge through a recommendation for nurse educators to incorporate storytelling through use of guest speakers. The guest speaker provides a "lived experience" that will connect the affective domain of learning with emotional intelligence. A guest speaker can discuss any "lived experience" for an array of diseases, mental health, spirituality, end-of-life, maternal, pediatric illness, social disparities, etc. Educators should provide the theoretical content prior to the guest speaker's story so that students already have a cognitive understanding of the disease process and can stay engaged in the learning experience. Additionally, the educator should provide the students with a reflective period after the guest speaker has left, which will afford students additional time for developing clinical judgment. Students should be encouraged to ask questions, which will clarify any misconceptions or confusion from previously learned material. This reflective time will also provide students the opportunity to have an outlet for emotions that developed from listening to the guest speaker. The formulation of emotions will guide future patient encounters. 


\section{Limitations}

Several limitations to this study exist. The demographics of the sample are predominately female, Caucasian, and of similar age. The sample size was small, although this was a qualitative study. Additionally, the study was completed in one school of nursing. A study identifying quantitative data related to emotional intelligence, development of clinical judgment, and longitudinal implementation in the clinical setting would provide depth to the science of nursing education.

\section{Conclusions}

Teaching to the cognitive and psychomotor learning domains are two methods easily incorporated in prelicensure nursing programs. Teaching to the affective learning domain is more difficult, but evidence from this study suggests that educators could employ the affective domain through emotional intelligence when preparing educational opportunities to meet student learning needs [22, 27]. A teaching strategy of storytelling with a guest speaker sharing their "lived experience" is an effective method of assisting students in developing emotional intelligence, gaining a better cognitive understanding of a disease process, and developing clinical judgment.

\section{References}

[1] Anderson, L. W. and Krathwohl, D. R., et al (Eds.) (2001) A Taxonomy for Learning, Teaching, and Assessing: A Revision of Bloom's Taxonomy of Educational Objectives. Allyn \& Bacon. Boston, MA (Pearson Education Group).

[2] Dave, R. H. (1970). Psychomotor levels. In R. J. Armstrong (Ed.), Developing and writing behavioral objectives. Tucson, Arizona: Educational Innovators Press.

[3] Muzyk, A. J., Lentz, K., Green, C., Fuller, S., May, D. B., \& Roukema, L. (2017). Instructional design and assessment: Emphasizing bloom's affective domain to reduce pharmacy students' stigmatizing attitudes. American Journal of

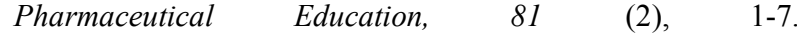
https://dx.doi.org/10.5688\%2Fajpe81235.

[4] Bleich, M. R., \& Jones-Schenk, J. (2016). Getting to the root of disparities: Social cognition and the affective domain. The Journal of Continuing Education in Nursing, 47 (10), 443-445. doi: 10.3928/00220124-20160920-04.

[5] Rice, E. (2015). Predictors of successful clinical performance in associate degree nursing students. Nurse Educator, 40 (4), 207-211. https://doi.org/10.1097/nne.0000000000000136.

[6] Shanta, L., \& Gargiulo, L. (2014). A study of the influence of nursing education development of emotional intelligence. Journal of Professional Nursing, 30 (6), 511-520. https://doi.org/10.1016/j.profnurs.2014.06.005.

[7] Britiller, M. C., Ramirez, L. Q., Ramos, F. M., Reyes, D. M., Salazar, K. D., \& Sandoval, J. A. (2014). Nurse educator's affective teaching strategies. Asia Pacific Journal of Multidisciplinary Research, 2 (1), 6-13.

[8] Krathwohl, D. R. (2002). A revision of bloom's taxonomy: An overview. Theory into Practice, 41 (4), 212-218. DOI:

\subsection{7/s15430421tip4104_2.}

[9] Bloom, B., Englehart, M., Furst, E., Hill, W., \& Krathwohl, D. (1956). Taxonomy of educational objectives: The classification of educational goals. Handbook I: Cognitive domain. New York, Toronto: Longmans, Green.

[10] Krathwohl, D. R., Bloom, B. S., \& Masia, B. B. (1964). Taxonomy of educational objectives: The classification of educational goals. Handbook II: The affective domain. New York: David McKay Company.

[11] Davidson, M. R. (2004). A phenomenological evaluation: Using storytelling as a primary teaching method. Nursing Education in Practice, 4 (3), 184-189. https://doi.org/10.1016/s1471-5953(03)00043-x.

[12] Petty, J. (2020). Creating stories from parents' premature birth experiences to engender empathy in nursing students. University of Herfordshire Research Archive (Dissertation). http://hdl.handle.net/2299/22635.

[13] Phillips, C., Bassell, K., \& Fillmore, L. (2017). Storytelling and reflective pedagogy: Transforming nursing education through faculty development. American Journal of Health Sciences, 8 (1), 7-17. https://doi.org/10.19030/ajhs.v8i1.9953.

[14] Schwartz, M., \& Abbott, A. (2007). Storytelling: A clinical application to undergraduate nursing students. Nurse Education in Practice, 7 (3), 181-186. DOI: 10.1016/j.nepr.2006.06.005.

[15] Stein, D. (2009). Storytelling: An adjunct to learning. Journal of Continuing Education in Nursing, 40 (7), 296-297. https://doi.org/10.3928/00220124-20090623-10.

[16] Timbrell, J. (2017). Instructional storytelling: Application of the clinical judgment model in nursing. Journal of Nursing Education, $56 \quad$ (5), 305-308. https://doi.org/10. 3928/01484834-20170421-10.

[17] Ward, T. D. (2015). Do you heat what I hear? The impact of a hearing voices simulation on affective domain attributes in nursing students. Nursing Education Perspectives, 36 (5), 329-331. https://doi.org/10.5480/14-1448.

[18] Pence, P. L. (2020). Telling stories to help undergraduate students learning concepts on genetics. Journal of Nursing $\begin{array}{llll}\text { Education, } & 59, & (8),\end{array}$ DOI:10.3928/01484834-20200723-14.

[19] Mayer, J. D., Salovey, P., \& Caruso, D. R. (2004). Emotional intelligence: Theory, findings, and implications. Psychological Inquiry, $\quad 15 \quad$ (3), 197-215. https://psycnet.apa.org/doi/10.1207/s15327965pli1503_02.

[20] Mayer, J. D., Salovey, P., \& Caruso, D. R. (2008). Emotional intelligence: New ability or eclectic traits? American $\begin{array}{llll}\text { Psychologist, } & 63 & \text { (6), }\end{array}$ https://psycnet.apa.org/doi/10.1037/0003-066X.63.6.503.

[21] Codier, E., \& Codier, D. D. (2017). Could emotional intelligence make patients safer? American Journal of Nursing, 117 (7), 58-62.

https://doi.org/10.1097/01.naj.0000520946.39224.db.

[22] Hutchinson, M., Hurley, J., Kozlowski, D., \& Whitehair, L. (2017). The use of emotional intelligence capabilities in clinical reasoning and decision-making: A qualitative, exploratory study. Journal of Clinical Nursing, 27 (3-4), e600-e610. https://doi.org/10.1111/jocn.14106. 
[23] Fernandez, R., Salamonson, Y., \& Griffiths, R. (2012). Emotional intelligence as a predictor of academic performance in first-year accelerated graduate entry nursing students. Journal of Clinical Nursing, 21 (23-24), 3485-3492. https://doi.org/10.1111/j.1365-2702.2012.04199.x.

[24] Tanner, C. (2006). Thinking like a nurse: A research-based model of clinical judgment in nursing. Journal of Nursing Education, $\quad 45 \quad$ (6), 204-211. https://doi.org/10.3928/01484834-20060601-04.
[25] Thorne, S. (2008). Interpretive description. Left Coast Press, Walnut Creek.

[26] Lincoln, Y. S., \& Guba, E. G. (1985). Naturalistic inquiry. Newbury Park, CA: Sage Publications.

[27] Landis, P. (2018). When patients backslide into their back story: Can emotional intelligence help emergency nurses? Journal of Emergency Nursing, 44 (6), 650-651. https://doi.org/10.1016/j.jen.2018.07.015. 